WellBeing International

WBI Studies Repository

1984

\title{
Logic and Limits of Animal Liberation
}

Edward R. Bennett
University of Georgia

Follow this and additional works at: https://www.wellbeingintlstudiesrepository.org/acwp_awap

Part of the Animal Studies Commons, Civic and Community Engagement Commons, and the Politics and Social Change Commons

\section{Recommended Citation}

Bennett, E.R. (1984). Logic and limits of animal liberation. In M.W. Fox \& L.D. Mickley (Eds.), Advances in animal welfare science 1984/85 (pp. 89-99). Washington, DC: The Humane Society of the United States.

This material is brought to you for free and open access by WellBeing International. It has been accepted for inclusion by an authorized administrator of the WBI Studies Repository. For more information, please contact wbisr-info@wellbeingintl.org.

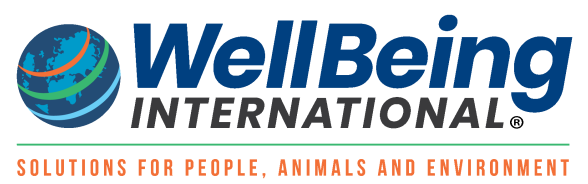




\section{LOGIC AND LIMITS \\ OF ANIMAL LIBERATION}

\section{Edward R. Bennett}

Department of Medical Microbiology

School of Veterinary Medicine

University of Georgia

Athens, GA 30605

\section{INTRODUCTION}

The current interest in treatment towards animals goes beyond the focus of isolated instances of brutality and encompasses the advocacy of significant changes in our traditional attitudes toward animals. In one year (1980) an estimated 2,054,281,000 hogs, beef, lamb, and poultry were raised on farms and slaughtered in the U.S.* (Agricultural Statistics 1981), and 1,653,385 laboratory animals were used by facilities registered with the United States Department of Agriculture (USDA 1974). Adding to this the number of related animal industries such as textiles, farm equipment manufacturing, cosmetics and drug industries, restaurants, and groceries, it is easy to appreciate the broad spectrum of changes which would result from significant changes in our relationship with animals. Since all individuals have an interaction with animals, at least by the animal products they choose to purchase (or not to purchase), there has been a proliferation of viewpoints concerning the treatment of animals. This paper will primarily consider Peter Singer's arguments presented in his book, Animal Lib- 
eration (1975), because it is a popular thesis which is objective and logically derived.

\section{DEFINITIONS}

Before considering views about our treatment of animals, it will be helpful to define and document several key terms.

\section{Speciesism}

Speciesism is a term used by Singer (1975) to mean "...a prejudice or attitude of bias toward the interests of members of one's own species and against those of members of other species."

\section{Pain}

The common dictionary definition of pain is "a distressing sensation as of soreness or mental suffering as applied to humans and other animals." (Oxford Universal Dictionary 1955). When it is applied to lower invertebrates Singer (1975) says "most mollusks are such rudimentary beings that it is difficult to imagine them feeling pain, or having other mental states." As a logical philosopher Singer admits that it is not yet possible to determine a precise line between organisms that feel pain and those that do not, but as an advocate for animal liberation, Singer (1975) says that "...somewhere between a shrimp and an oyster seems as good a place to draw the line as any..."

\section{Stress}

Stress is often imprecisely used as a catch-all term for unknown factors which adversely affect an animal. A precise definition which has a physiologically measurable effect has been given by Hans Selye (1976). He defines stress as "the state manifested by a specific syndrome which consists of all the non-specifically induced changes within a biological system." The specific syndrome is called the General Adaptation Syndrome (G.A.S.) and consists of a specified alarm reaction, a stage of resistance, and a stage of exhaustion. The alarm reaction can be measured physiologically and consists of adrenocortical enlargement, atrophy of the thymicolymphatic organ and gastro-intestinal ulcers. So stress is the result of nonspecific factors that cause the G.A.S. This definition permits us to recognize stress and quantify it by measuring the alarm reaction. It is important to note that stress can be good or detrimental depending upon how the biological systems adapt to the detrimental effects of stress.

\section{Equal Consideration}

The concept of equal consideration is used by Singer to determine the parameters of acceptable treatment. "The basic principle of equali- 
ty does not require equal or identical treatment, it does require equal consideration." (Singer 1975). Equal consideration is the result of recognizing that the fundamental common capacity between humans and animals is the capacity to suffer or feel pleasure. Singer (1975) quotes Jeremy Bentham, "The question is not can they (animals) reason? nor can they talk? but, can they suffer?" If equal consideration is given, then animals should not be subject to anymore suffering than we find permissible in humans. He goes on to state:

... if we consider it wrong to inflict that much pain on a baby for no good reason then we must, unless we are speciesists, consider it equally wrong to inflict the same amount of pain on a horse for no good reason (Singer 1975, p. 16).

\section{SINGER'S PHILOSOPHY OF ANIMAL LIBERATION}

Singer (1975) states that animals and humans share the capacity to suffer pain or experience pleasure and that this capacity is the defining element that gives an individual interests: "The capacity for suffering and enjoyment is a prerequisite for having interests at all..." We can attempt to compare the amount of suffering or pleasure between species, but Singer (1975) admits that precise comparisons are difficult.

It is probably true that comparisons of suffering between members of different species cannot be made precisely, but precision is not essential (p. 17).

Precision is not essential since a great amount of suffering will be eliminated even if a change in treatments is limited to comparisons of suffering which can be made with certainty. Our treatment of different species should not permit them to suffer any more than we allow for any one species. "No matter what the nature of the being, the principle of equality requires that its suffering be counted equally with like suffering'" (Singer 1975). In Singer's theory the capacity to feel pain is the only factor which should be used to give equal consideration to individuals regardless of species. However, on the subject of killing, he allows other factors to influence the principle of equal consideration. He says that it is just as wrong to kill animals when under the same conditions, we would not kill humans. He makes the claim that:

Just as most humans are speciesists in their readiness to cause pain to animals when they would not cause a similar pain to humans for the same reason, so most humans are speciesists in their readiness to kill animals when they would not kill humans (Singer 1975, p. 18). 
But he does allow that factors such as "self-awareness, intelligence, the capacity for meaningful relations with others and so on...may be relevant to the question of taking life" (Singer 1975).

\section{ARGUMENTS}

Since there are many proponents of animal liberation, there are a number of arguments which lack logical theory, are based on misconceptions, and allude to anthropomorphism. Several examples can be cited in Jonny Frank's (1979) article on factory farming. Frank (1979) says that a baby pig "...suffers abuse just like its mother: within a day or two of birth, the young piglet has its ears knotched, its teeth clipped, its tail docked, and if male, is castrated as well." He never tries to compare the pain (if any) to pain in humans. Is ear knotching in the pig more painful than ear piercing in humans? When Frank (1979) states that pigs' teeth are clipped, he does not explain that only the sharp tips of these needle teeth are removed (Esminger 1970). He also fails to say that the reason the sharp teeth are clipped is to prevent injury to the other piglets and to the sow's udder (Esminger 1970). The fact that the piglets show no apparent signs of pain since they continue to nurse and fight with littermates (a normal pecking order behavior) makes it necessary for Frank (1979) to justify why he calls this practice abusive. A similar argument can be made for tail docking and castration.

Frank (1979) gives a romaticized view of a good non-abusive farm in his statement that "Only a few small dairy farms conform to the traditional pastoral scene, permitting the cows to graze in outdoor pastures during good weather." He makes no attempt to objectively evaluate the suffering an animal may have in confinement versus pasture. The fact that he envisions cattle grazing only in "good weather" reveals his affinity for emotion rather than detached reasoning.

Unbounded by logic Frank goes on to boldly delve into the inner psyche of a bovine and claims "...the separation of the calf from its mother causes psychological harm." This statement is "justified" in a footnote: "Mason visited calf barns and calves would attempt to "suckle a finger, hand, or part of our clothing.' A farmer explained that they always do this because "they want their mothers I guess." The farmer's statement hardly qualifies as expert analysis and does not justify the leap from the observation of suckling behavior to the assumption of psychological harm.

As an advocate of animal liberation, Singer (1975) also occasionally disregards his philosophical objectivity: 
Flesh taints our meals. Disguise it as we may, the fact remains that the centerpiece of our dinner has come to us from the slaughterhouses, dripping blood. Untreated and unrefrigerated, it soon begins to putrefy and stink. When we eat it, it sits heavily in our stomachs, blocking our digestive process until, days later, we struggle to excrete it (p. 183).

Singer (1975) does not justify how his perception of sauces or creative gourmet techniques constitutes a disguise for meat, not to mention the many times meat is served plain with decoratively styled vegetables. His reference to dripping blood may be symbolic. If not, he makes the common mistake of confusing blood with the inter- and extra-cellular fluid (not blood) that contains the pigment myoglobin, which reacts with oxygen and turns red. Any blood that still remained on the carcass would be coagulated by the time it leaves the slaughter house, and it would not be dripping. Since the decay to which Singer objects also occurs in fruits and vegetables, his comment is not a valid argument. Finally, to justify the statement that meat blocks our digestive system, Singer refers to research which compares the mean transit time of food moving through the digestive tract of nonvegetarians with that of vegetarians. Although there is speculation about the correlation between the increased transit time and increased incidence of colon cancer, the implication of this speculation, if it is correct, would not necessarily be that meat is bad but that the diet should contain more roughage.

There are a number of common objections that are made against Singer's theory of animal liberation, but the nature of the theory is such that most objections can be shown to deny equal consideration on the basis of irrational speciesism. The practical application of animal liberation would cause significant changes in the ways animals are raised on farms (if they are raised at all) and the use of animals in research. The objective of farm management like other businesses is to produce the maximum product (milk, eggs, meat, fiber) at the minimum cost. The criticism raised by animal liberationists is that equal consideration to the interests of animals is not a factor in farm management. The common objectives often raised by agricultural interests are: (Singer 1975)

1. Domestic animals are selectively bred by man for the purpose of farming so without agriculture the animals would not exist.

2. The farm animals were born and raised on a farm and have never known other conditions so they do not know what it means to live independently.

3. Conditions on the farm "... are no worse than conditions in the wild where animals are exposed to cold, hunger and predators." 
Singer's reply to the first criticism is that "once a being exists, we have an obligation to avoid making that being suffer unnecessarily, but we have no obligation to nonexistent beings."

His response to the second criticism is that "animals feel a need to exercise, stretch their limbs or wings, groom themselves, and turn around, whether or not they have ever lived in conditions that permit this." (Singer 1975)

Singer (1975) answers the third criticism by saying that the choice "is not between life on a factory farm and life in the wild, but whether animals destined to live on factory farms and then be killed for food should be born at all."

Ewbank (1973) has attempted to classify groups of behavior changes that may be caused by intensive confinement management.

Type I...abnormal behavior patterns are associated with pathological changes and obvious economic loss.

Type II...abnormal behavioral patterns occurring with little or no evidence of economic loss.

Type III...changes are qualitative alterations in otherwise normal behavioral patterns and are detectable only by systematic observation.

He says that it is difficult to assess the behavioral changes in Types II and III but says that Type I problems are "self-evident." Singer (1975) would believe that there could be significant changes in our treatment of animals even if we only considered the Type I behavior. He states:

Even if we were to prevent this infliction of suffering on animals only when it is quite certain that the interests of humans will not be affected to anything like the extent that animals are affected, we would be forced to make radical changes in our treatment of animals...(p. 17).

\section{ANIMAL RIGHTS}

The debate about animal rights complicates the issue of animal liberation. We can classify two types of rights-legal and moral. We may define legal rights as those that society assigns while moral rights can be considered as those that society recognizes as inherent. According to Stone as reported by Dichter (1979) “...there is no generally accepted standard for legal rights..." But Stone (Dichter 1979) defines four conditions for having legal rights:

1. need an authoritative body to review and enforce rights, 
2. must institute legal action at the animals' behest,

3. court must take injury into account,

4. relief must run to the benefit of the animal.

The definition of moral rights may cause more debate. One argument is that "animals are capable of suffering and of frustration and therefore have interests in the same manner that senile persons, infants, and brain damaged people have rights, even though they are intellectually deficient and cannot claim them." (The Futurist 1979) Singer (1975) also shares this view when he says "to avoid speciesism, we must allow that beings which are similar in all relevant respects have a similar right to life-and mere membership in our own biological species cannot be a morally relevant criterion for this right."

Michael A. Fox (1978) argues that since there are no "...attributes that all humans without exception share in common...even the capacity of humans to experience pain and pleasure falls short of universality...," we should "...shift our attention instead to capacities that are nearly or virtually universal among humans." By doing this we can find attributes that humans have and animals do not so Fox (1978) concludes "...that the concept of a moral right to equal treatment makes no sense except as applied to humans."

This argument misses the point of Singer's (1975) argument that the criterion is not a universal capacity for pain or pleasure within a species but that individuals, regardless of their species, that have the same capacity for pain or pleasure, should have equal consideration in treatment with respect to this capacity. Singer (1978) says:

I do not deny that normal human beings may possess capacities lacked by both retarded humans and animals. My point is that anyone wishing to defend our existing attitudes has to find some basis for attributing rights which does apply to all human beings but not to other animals. I claim that no such basis exists.

To avoid this criticism, Fox (1978) adds an essential statement that "...autonomy, which thus entails certain cognitive capacities, is necessary (and, together with the capacity to enjoy or suffer, sufficient) for the possession of moral rights." Unfortunately, he does not give any justification for this point. "How can the above entailments be defended? I cannot give full treatment to this important argument here..." Without providing this justification Fox's theory is incomplete and fails to challenge Singer's argument. 


\section{OTHER ARGUMENTS}

We may raise the question about our role in the naturally occurring predator-prey relationship which clearly violates the principle of equal consideration. Singer (1975) says we should not interfere because "...judging by our past record, any attempt to change ecological systems on a large scale is going to do far more harm than good." So apparently if there was a way to eliminate the actions of carnivorous species without causing major changes in the ecological balance, it would be justified.

A strong argument is to ask what animal liberationists plan to do about wild animals which feed on the plant crops. Singer's (1975) response is to suggest the hope that "we may eventually develop methods of limiting the numbers of those species whose interests are genuinely incompatible with our own." But the main point is that Singer's philosophy is utilitarian and permits killing animals, after giving equal consideration if there are conflicting interests. Nozick (1974) outlines these characteristics of utilitarian theory:

1. maximize happiness for all living beings,

2. stringent side constraints on what a human may do to another human and

3. animals may be used or sacrificed for the benefit of other people or animals only if those benefits are greater than the loss inflicted.

Singer assumes that those side constraints for human treatment are based on the capacity to suffer and should be applied among all individuals according to their capacity to suffer regardless of the species. But we may argue that those side constraints are based on other factors in addition to suffering.

As mentioned above Singer (1975) says that the factors such as "self-awareness, intelligence, the capacity for meaningful relations with others, and so on, are not relevant to the question of inflicting pain-since pain is pain,...these capacities may be relevant to the question of taking life." The reason that other capacities are permitted in the question of killing is because:

...people hold widely differing views about when it is legitimate to kill humans as the continuing debates over abortion and euthanasia attest. Nor have moral philosophers been able to agree on exactly what it is that makes it wrong to kill humans, and under what circumstances killing a human being may be justifiable (Singer 1975, p. 18). 
So the argument "pain is pain" cannot be countered by saying killing is killing since there are different factors which influence when killing may be morally justified in humans. The argument that the capacity to suffer is the only criterion to be used in equal consideration because "pain is pain," is justified by the assumption that people must hold a common view about when it is legitimate to cause pain in humans and that moral philosophers must be able to agree when pain is justified. Singer does not state this, but it is the logical parallel of his argument on killing applied to pain. This is the implied explanation for the statement "pain is pain." This is the fundamental point where we can raise strong objections to Singer's theory of animal liberation.

While Singer's theory is utilitarian with respect to killing animals, he assumes that there is a moral concensus on human suffering which is based only on the capacity to suffer and is free of other utilitarian factors. Singer would allow factors in addition to suffering in the debates about abortion or the death penalty since these topics involve the question of killing. But in subjects such as slavery or civil rights, Singer would hold that the only necessary factor is the amount of suffering. In this respect, Singer's theory is not utilitarian since it violates Nozick's (1974) third characteristic of a utilitarian position that "... animals may be used or sacrificed for the benefit of other people or animals only if those benefits are greater than the loss inflicted." It may be that Singer assumes that these other factors are used in determining treatment in humans, but he cannot simply give equal consideration to other species based only on the capacity to suffer because the amount of suffering was not the only factor considered in determining the moral standard of treatment in the first place.

Our treatment of other people is based on many factors, one of which is emotional attachment. We see this in animals with maternal attachment or rejection, and we observe it in humans by the intuitive observation that we are more sensitive to the pain or pleasure of people to whom we have closer psychological bonds. Just as we make emotional bonds to certain human individuals, we also make bonds to animals and this bond affects our treatment of them. "Although regarded as acceptable fare on the continent, eating horse meat is akin to cannibalism in Britain" (The Economist 1978). One reason that a laboratory animal which may have "a higher degree of self-awareness and a greater capacity for meaningful relations with others than a severely retarded infant"' (Singer 1975), may still be used in research rather than the infant, is because there is a greater emotional attachment made to the infant. This theory is not speciesist since it also holds that it may be wrong to take someone's pet and use it in an experiment since there is an emotional bond made to the pet animal. Ad- 
mittedly this factor elevates the human species since it always applies to humans and it is not always applicable to animals. However, it does not make the theory speciesist since it does not imply that only the presence or lack of emotional bond should determine treatment. It only suggests that other factors, in addition to the capacity to suffer, should influence our treatment of animals just as it influences treatment of other humans.

\section{CONCLUSION}

In the debate about animal liberation, it is necessary to define terms and focus on philosophically clear arguments which minimize casual inaccuracies and are free from emotional embellishment. We have considered Singer's theory of animal liberation and can conclude that to be acceptable, Singer must allow other factors in addition to suffering to directly influence equal consideration. It was argued that this can be done without resulting in speciesism. The practical application of the theory will still result in significant non-speciesist re-evaluation of treatment of animals. 


\section{REFERENCES}

Agricultural Statistics 1981. United States Government Printing Office, Washington, D.C. 0-343-911.

Dichter, A. 1979. Legal definitions of cruelty and animal rights. Boston College Environmental Affairs Law Review 7:147-64.

The Economist. 1978. Eating pets is wrong. July 1:26.

Ensminger, M.E. 1970. The Stockman's handbook. Danville, Illinois:The Interstate Printers and Publishers, Inc.

Ewbank, R. 1973. The trouble with being a farm animal. New Scientist 18:172-3.

Fox, M.A. 1978. 'Animal liberation': A Critique. Ethics 88:106-18.

Frank, J. 1979. Factory farming: An imminent clash between animal rights activists and agribusiness. Boston College Environmental Affairs Law Review 7:423-61.

The Futurist. 1979. Rethinking animal rights. June:239.

Nozick, R. 1974. Anarchy, state, and utopia. New York:Basic Books, Inc.

Oxford Universal Dictionary, 1955. Third Edition.

Selye, H. 1976. The stress of life. New York:McGraw-Hill Book Co.

Singer, P. 1975. Animal liberation. New York:Avon Books.

1978. The fable of the fox and the unliberated animals. Ethics

88:120-1.

United States Department of Agriculture. June 1974. Animal Welfare Enforcement. 1973 Report of the Secretary of Agriculture to the President of the Senate and the Speaker of the House of Representatives:pp. 19-21. 